Session 2268

\title{
Assessing Undergraduate Mechanics Courses
}

\author{
John C. Duke, Jr. and Don H. Morris \\ Department of Engineering Science and Mechanics \\ Virginia Tech
}

\begin{abstract}
A uniform procedure for assessing courses for continuous improvement, consistent with ABET EC2000, has been developed at Virginia Tech in the Department of Engineering Science and Mechanics. This paper will describe the details of this procedure and how the procedure fits within an overall process for Student Outcomes Assessment. Specific examples of the course assessment process and how the assessment data are used to evaluate student achievement as well as form the basis for recommendations for course improvement will be discussed.
\end{abstract}

\section{Introduction}

Continuous improvement of student learning as well as maintaining relevancy of the course content are the objectives of ABET EC $2000^{1}$. To support such an approach a process for assessing individual courses as well as student outcomes from the overall program is needed. However, for faculty members at a Research I university their responsibilities include not only teaching, but also research and outreach. As a consequence, the process must be effective and efficient.

The process developed and implemented in the Department of Engineering Science and Mechanics at Virginia Tech will be described and examples of the data collected presented. The course assessment outcomes assessment process is part of an overall effort to sustain an outstanding undergraduate educational program in engineering science and mechanics at a comprehensive land grant Research I university, Fig. 1. The undergraduate program objectives are maintained consistent with the needs of its constituents as well as the University and College of Engineering strategic plans through this process.

\section{Course Assessment Process - The Big Picture}

The overall process for course assessment is depicted schematically in Fig. 2. 


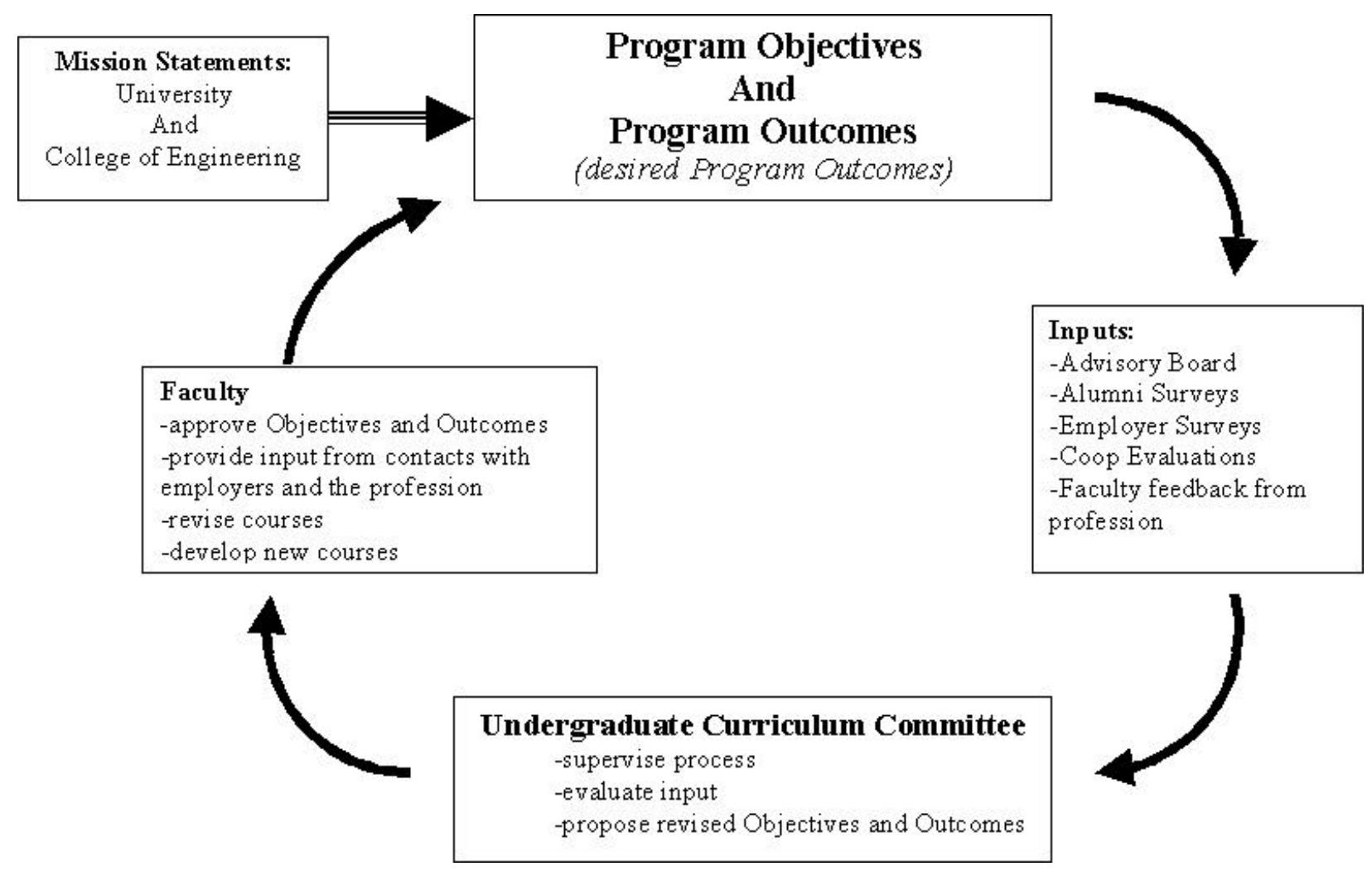

Fig. 1. Process for continuously assessing the program objectives and outcomes

The course assessment process is designed to achieve two main objectives, the assessment of the individual course and assurance that the part of the overall program of study supported by the learning objectives of that course are also fulfilled. The faculty member instructor performs the course assessment and his, or her, evaluation is reported to the Undergraduate Curriculum Committee (UGC). This committee examines the individual reports to assure that the desired Student Outcomes are being achieved. The committee also considers any recommendations for curriculum changes as regards their impact on the overall program of study or for their potential impact on other courses. In that all curriculum changes must be approved by the departmental faculty and in some instances also require extra-departmental approval the UGC coordinates the necessary follow-up actions. Courses that support the undergraduate program of study as well as courses taught as a service to other departments are assessed using the same procedure.

\section{Course Assessment Process - for the individual course}

The faculty member instructor is recognized as an expert for the course subject matter and is relied on to develop appropriate tools for assessing each of the course learning objectives. Table 1 is an example of the form used to report a summary of the assessment results and any recommendations based on the evaluation of the results. Any particular assessment tool, homework, group project, laboratory reports, quizzes, testing, or combination deemed necessary by the instructor could be used. The assessment might be used to monitor (M) or summatively assess (S) the student achievement. 


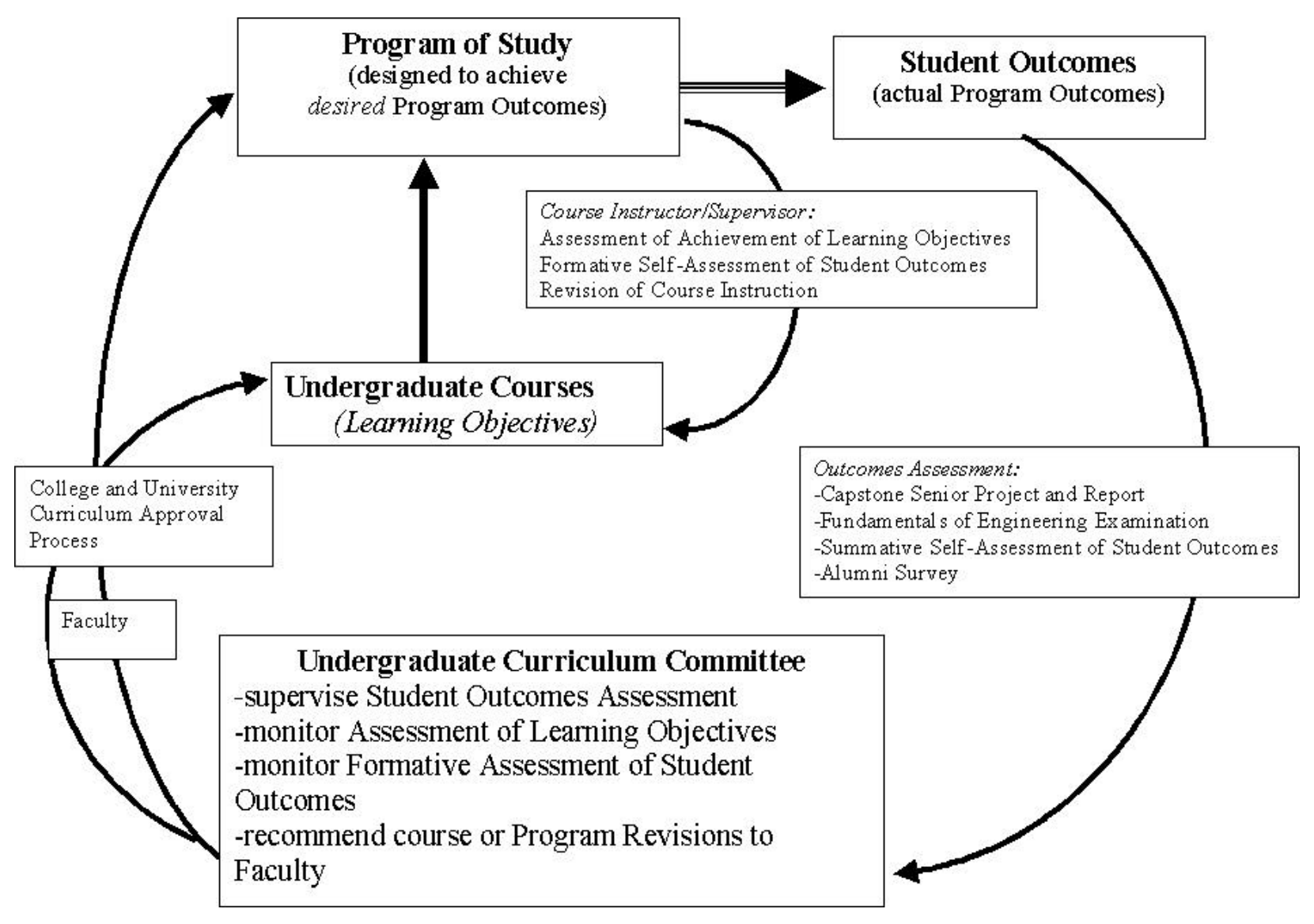

Fig. 2. Schematic diagram depicting the process for course assessment as well as student outcomes

The instructor is expected to determine if the students satisfactorily achieve the course learning objectives. Although somewhat arbitrarily, it was decided that if less than $75 \%$ of sophomore students, $80 \%$ juniors, and $90 \%$ of seniors achieve a course objective then it is imperative that improvement be considered to improve student success. Of course, recognizing the inherent variability of assessing human subjects it is considered reasonable to delay any major changes until problem areas are confirmed by assessment from more than one offering of the course.

Furthermore, the instructor is only asked to determine how many students satisfactorily achieve each objective. It is assumed that instructors will continually consider proactive course improvements that will more effectively present course material even if the minimal levels are achieved. However if these levels are repeatedly not achieved it is assumed that either student preparation, or prerequisite course requirements, should be improved, or course coverage is overly ambitious, and the number of course learning objectives should be reduced.

Note: It is important to differentiate between minimally satisfying a learning objective and achieving a level of understanding that satisfies the instructor. Most instructors desire students to achieve an "A" or "B" level of understanding, but consider minimally satisfactory achievement a "D." Of course if all students just minimally satisfy a learning objective the instructor is likely to be concerned and seek to identify how to improve the student learning. 


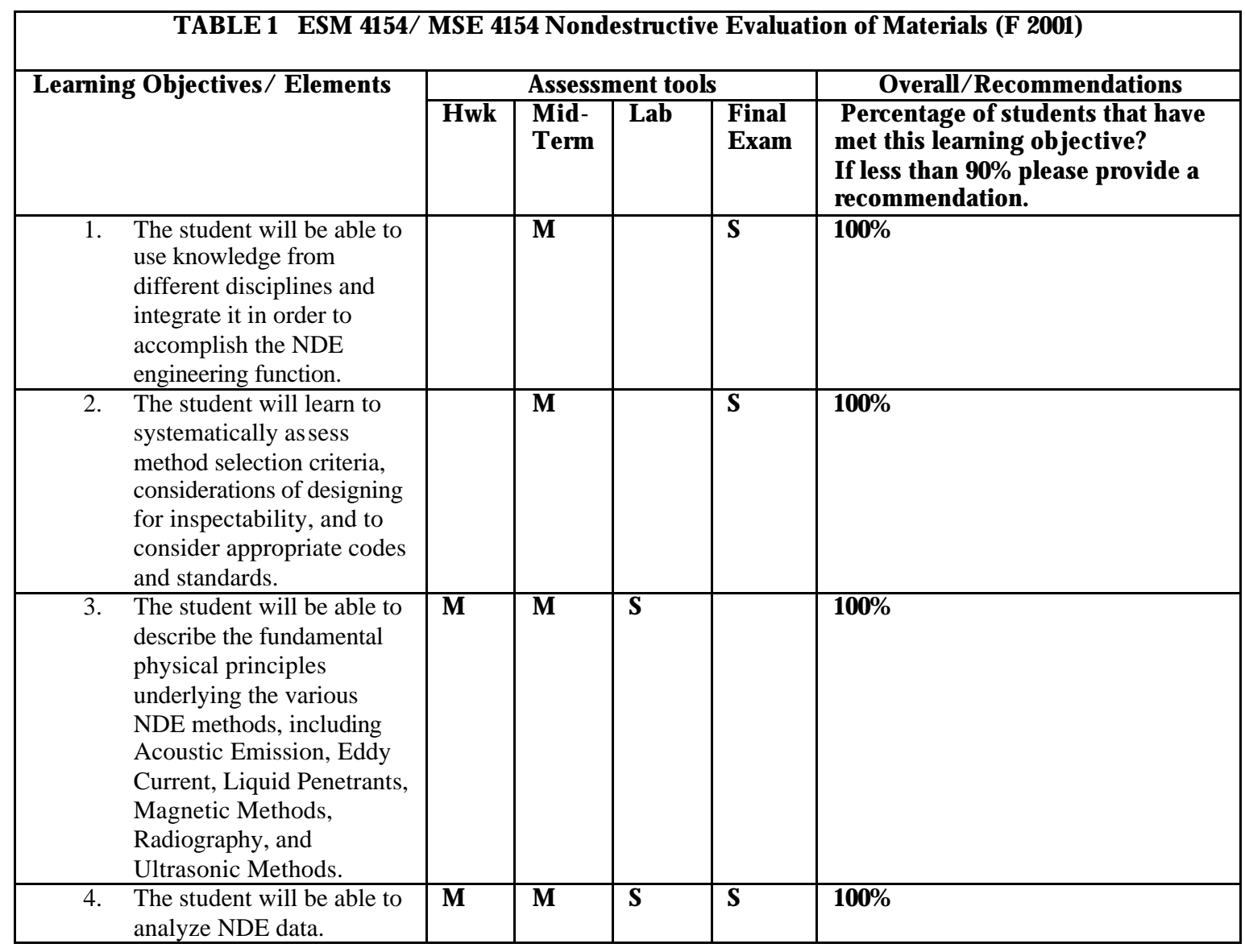

\section{Outcomes Assessment}

Assessing how successful the Program of Study has been in supporting student achievement of the Program Outcomes requires both a formative component and a summative component. Since various Course Learning Objectives from different courses support the Program Outcomes finally assessing whether students have achieved the outcomes upon graduation is accomplished by assessment in the senior capstone design course and supplemented by the performance on the nationally-normed Fundamentals of Engineering examination. This course provides a learning experience that is anticipated to allow students to synergistically apply the assorted Course Learning Objectives so as to achieve the Program Outcomes. However, if this summative assessment suggests that an outcome is not being achieved it may not elucidate the root causes. Consequently at various intermediate points in the program a formative assessment can be done that can provide greater insight into impediments to the ultimate achievement of the outcomes. Of course any curriculum changes designed to improve the achievement of Program Outcomes will require careful consideration of assessment data for several years in order to observe the effects of these changes. 
Student self-assessment has been found to be helpful in identifying disparities between student achievement and student perception of their ability as well as levels of confidence. Recognizing the developing maturity level of the students, and even recent alumni, however, disparities in levels of confidence and levels of achievement are understandable. If such disparities occur where confidence is less than reality then it is advisable to seek ways to buoy the student confidence. The converse situation it more problematic and demands more careful attention.

\section{Refining the process}

Having transitioned into the process described above with dispatch, in preparation for an ABET accreditation visit, the road ahead suggests it will be advisable to refine the process. Although preliminary guidance regarding the new EC2000 criteria discouraged colleges from using the criteria verbatim retrospectively it is advisable to do exactly that and to supplement the "a-k" elements by additional criteria where appropriate. Of course rewording of the original criteria to more precisely define them in the context of the individual program is appropriate. However, presenting the case for program evaluation is far simpler if the program criteria and the EC2000 criteria have a one-to-one correspondence.

In addition, increased experience by faculty member instructors with the assessment process will lead to suggestions for refining the process. For example the arbitrarily set percentages for triggering a recommendation for course improvement are likely to be adjusted to more appropriately accomplish the Program Objectives.

\section{Summary}

A process for assessing courses, consistent with ABET EC2000, has been described. The process is efficient, a critical aspect for faculty members at a comprehensive land-grant Research I university.

\section{Bibliographic Information}

1. Engineering Criteria 2000, Program Self-Study Instructions, EC 2000 Visits, Accreditation Board for Engineering and Technology, Baltimore.

\section{Biographical Information}

John C. Duke, Jr. is a Professor of Engineering Science and Mechanics; he has over 20 years experience teaching mechanics courses.

Don H. Morris is a Professor of Engineering Science and Mechanics and is the Assistant Department Head with more than 30 years experience teaching mechanics courses. 